\title{
Satellite cell content in Huntington's disease patients in response to endurance training
}

\author{
Sandro Manuel Mueller ${ }^{1,2}$, Violeta Mihaylova', Sebastian Frese ${ }^{1,3}$, Jens A. Petersen', Maria Ligon-Auer ${ }^{1}$, \\ David Aguayo ${ }^{3}$, Martin Flück ${ }^{4}$, Hans H. Jung ${ }^{1 \dagger}$ and Marco Toigo $2,3,4^{*}+$
}

\begin{abstract}
Background: Skeletal muscle wasting is a hallmark of Huntington's disease (HD). However, data on myocellular characteristics and myofiber remodeling in HD patients are scarce. We aimed at gaining insights into myocellular characteristics of HD patients as compared to healthy controls at rest and after a period of increased skeletal muscle turnover.

Methods: Myosin heavy chain (MyHC)-specific cross-sectional area, satellite cell content, myonuclear number, myonuclear domain, and muscle fiber type distribution were determined from vastus lateralis muscle biopsies at rest and after 26 weeks of endurance training in HD patients and healthy controls.

Results: At the beginning of the study, there were no differences in myocellular characteristics between HD patients and healthy controls. Satellite cell content per MyHC-1 fiber $(P=0.014)$ and per MyHC-1 myonucleus $(P=0.006)$ increased significantly in healthy controls during the endurance training intervention, whereas it remained constant in HD patients ( $P=0.804$ and $P=0.975$ for satellite cell content per MyHC-1 fiber and myonucleus, respectively). All further variables were not altered during the training intervention in HD patients and healthy controls.

Conclusions: Similar skeletal muscle characteristics between HD patients and healthy controls at baseline suggested similar potential for myofiber remodeling in response to exercise. However, the missing satellite cell response in MyHC-1 myofibers following endurance training in HD patients points to a potential dysregulation in the exerciseinduced activation and/or proliferation of satellite cells. In the longer-term, impaired myonuclear turnover might be associated with the clinical observation of skeletal muscle wasting.
\end{abstract}

Keywords: Muscle mass, Muscle wasting, Stem cell, Plasticity, Remodeling

\section{Main text}

Huntington's disease (HD) is a neurodegenerative disorder with symptoms encompassing motor, cognitive, and psychiatric dysfunctions. While the initial research on this disease focused mainly on the central nervous system, other organs and tissues, such as skeletal muscle, have additionally gained attention in the scientific literature in the past few years. For example, several studies in HD patients reported energy metabolism dysfunctions

\footnotetext{
* Correspondence: marco.toigo@oym.ch

${ }^{\dagger}$ Hans H. Jung and Marco Toigo contributed equally to this work.

${ }^{2}$ Research and Performance Center for Elite Athleticism, OYM,

Lorzenparkstrasse 12, 6330 Cham, Switzerland

${ }^{3}$ Institute of Human Movement Sciences, ETH Zurich, Zurich, Switzerland

Full list of author information is available at the end of the article
}

in skeletal muscle [1-4] and skeletal muscle pathology was well-described in mouse models [5-7]. Because skeletal muscle wasting is regarded as a hallmark of HD, skeletal muscle mass was also investigated in recent publications. In these studies, no differences in whole-body fat-free mass or lean mass between HD patients and healthy controls could be detected [8-11]. These findings challenge the notion of skeletal muscle wasting, at least in early- to mid-stage HD patients. Moreover, data on muscle fiber cross-sectional areas, satellite cells, myonuclei, and myofiber remodeling upon exercise in HD patients remain scarce.

In the current preliminary study, we aimed at gaining insights into muscle fiber cross-sectional areas, satellite

(C) The Author(s). 2019 Open Access This article is distributed under the terms of the Creative Commons Attribution 4.0 International License (http://creativecommons.org/licenses/by/4.0/), which permits unrestricted use, distribution, and 
cell content, myonuclear content and myonuclear number of HD patients as compared to healthy controls at rest and after a period of increased skeletal muscle turnover. We reanalyzed muscle biopsy samples from a previous study [12]. Due to limitations in muscle tissue amount, we were not able to analyze all samples of the previous study. Muscle samples of nine HD patients (age: $51.7 \pm 7.9$ years, height: $1.74 \pm 0.05 \mathrm{~m}$, body mass: $75.9 \pm 11.2 \mathrm{~kg}$ ) and ten healthy control participants (age: $50.0 \pm 6.7$ years, height: $1.79 \pm 0.05 \mathrm{~m}$, body mass: $82.8 \pm$ $13.0 \mathrm{~kg}$ ) could be analyzed and the results thereof are presented in this report. According to the clinical

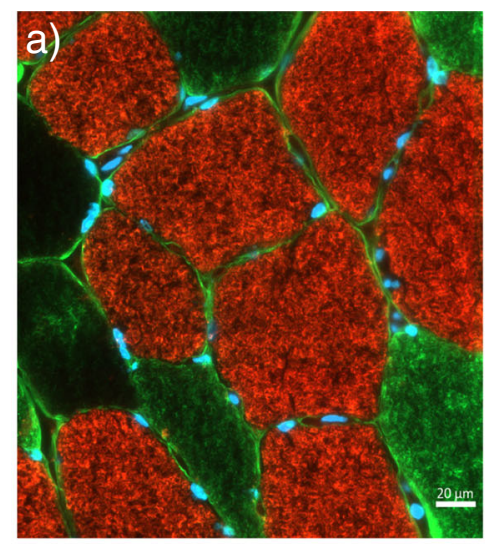

MyHC-1/MyHC-2A/MyHC-2X/Merosin/DAPI

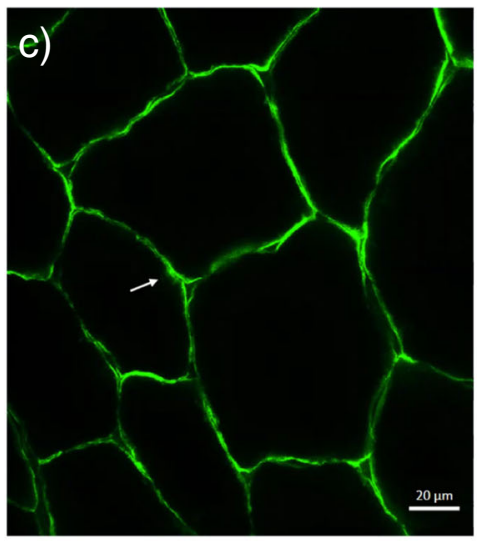

Merosin

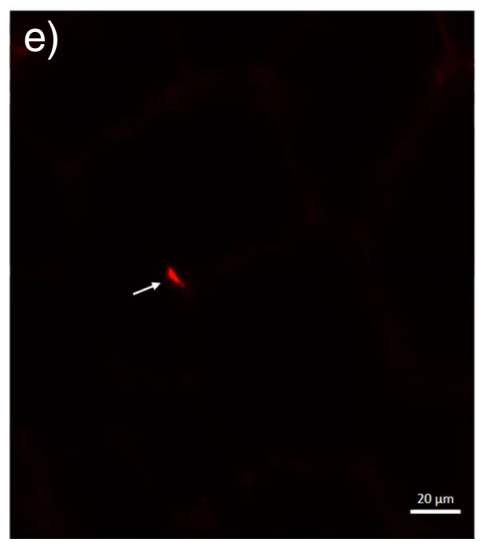

Pax7

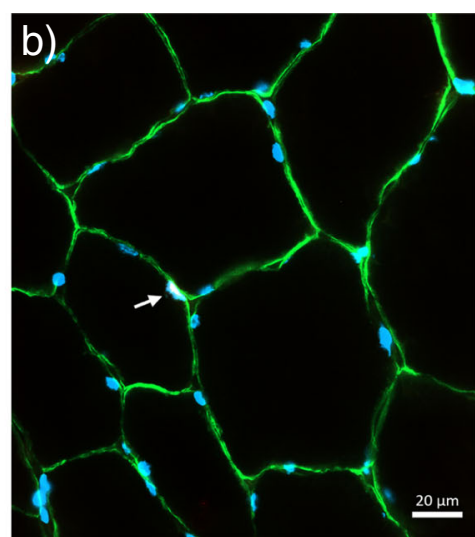

Merosin/DAPI/Pax7

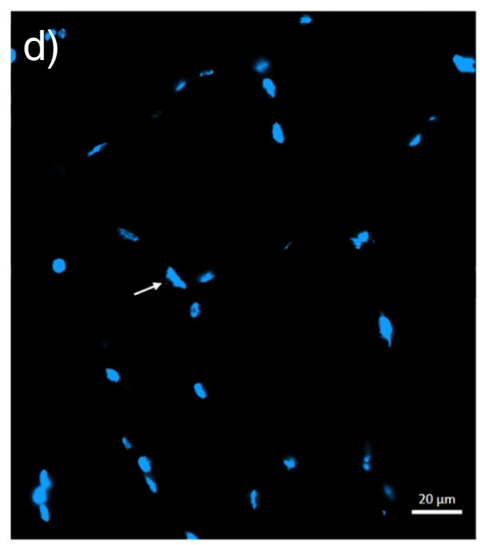

DAPI

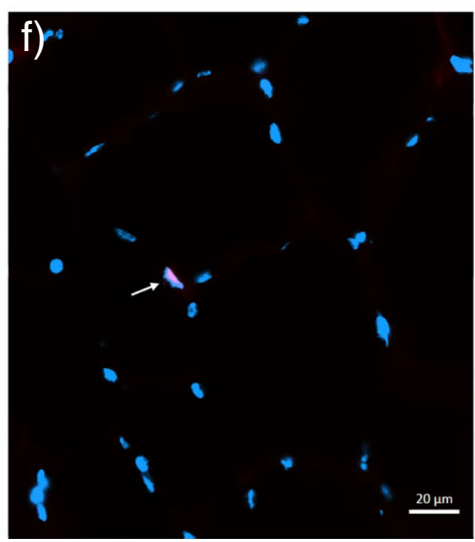

DAPI/Pax7

Fig. 1 Representative images of fiber type-specific analyses of skeletal muscle satellite cell content. a) Myosin heavy chain (MyHC) isoforms stained as follows: MyHC-1 (red), MyHC-2A (green), MyHC-2X (unstained, black), b) co-occurrence of Pax $7^{+}$cell (red) with subsarcolemmal myonucleus (blue) and cell border line (green), c) merosin staining for cell borders (green), d) subarcolemmal myonuclei (blue), e) Pax $7^{+}$cell (red), $\mathbf{f}$ ) co-occurrence of $\mathrm{Pax}^{+}$cell (red) with subsarcolemmal myonucleus (blue) 


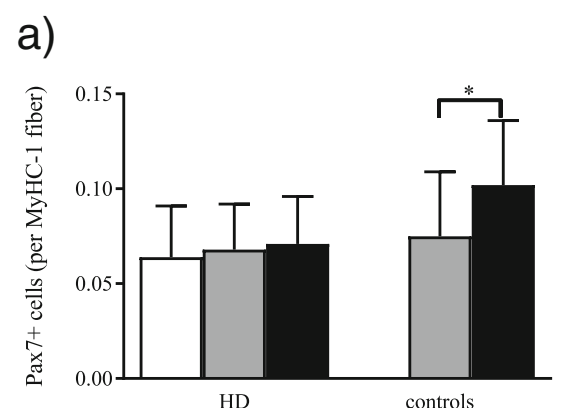

c)

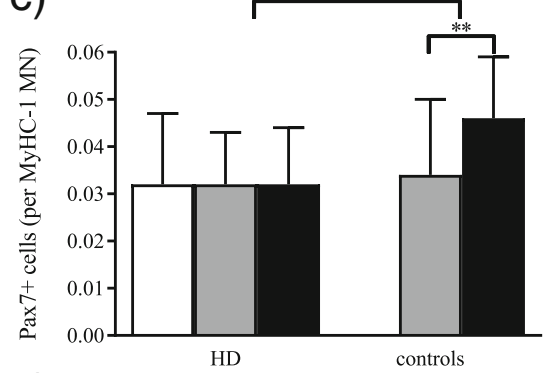

e)

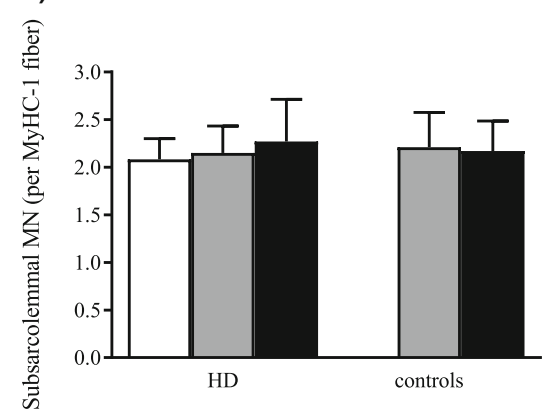

g)

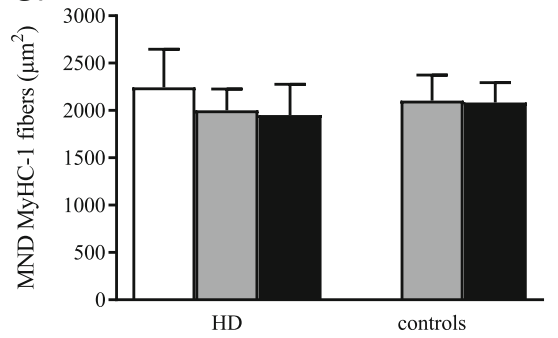

i)

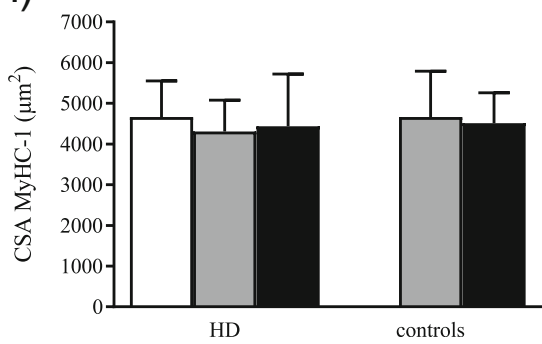

b)

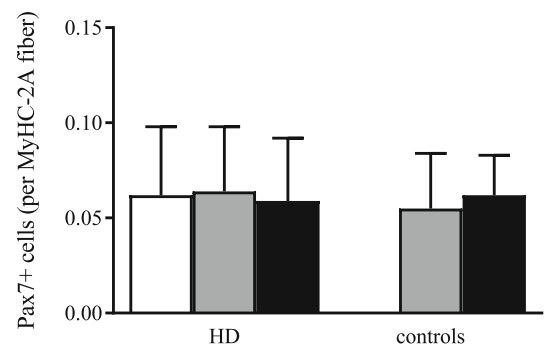

d)

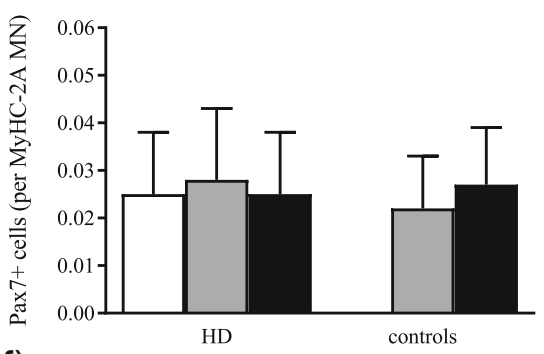

f)

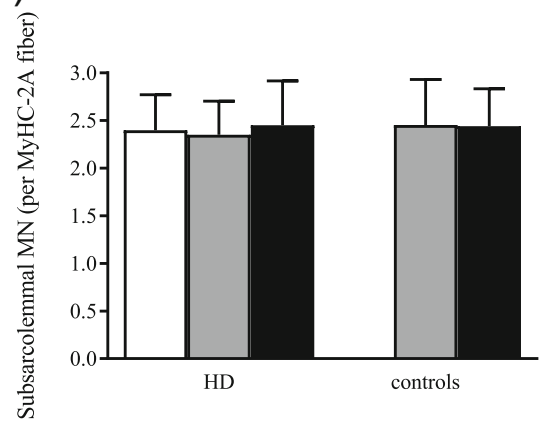

h)

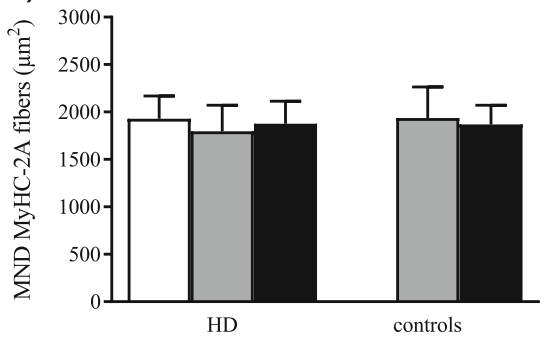

j)

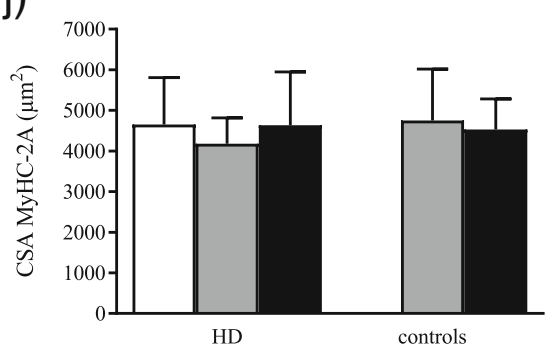

Fig. 2 (See legend on next page.) 
(See figure on previous page.)

Fig. 2 Baseline (white bars), pre- (grey bars) and post-training (black bars) values for HD patients $(n=9)$ and healthy control participants $(n=10)$ for satellite cell content a) per MyHC-1 fiber, b) per MyHC-2A fiber, c) per MyHC-1 fiber myonucleus (MN), d) per MyHC-2A fiber MN, for subsarcolemmal MN content in e) MyHC-1 fibers and $\mathbf{f}$ ) MyHC-2A fibers, for myonuclear domains (MND) in $\mathbf{g}$ ) MyHC-1 fibers and $\mathbf{h}$ ) MyHC-2A fibers, for cross-sectional area (CSA) of $\mathbf{i}) \mathrm{MyHC}-1$ fibers and $\mathbf{j}$ ) MyHC-2A fibers

assessments, the HD patients were classified as earlyand intermediate-stage of disease. Myosin heavy chain $(\mathrm{MyHC})$-specific cross-sectional area, satellite cell content, myonuclear number, and myonuclear domain were determined from vastus lateralis muscle biopsies at rest and after 26 weeks of endurance training in HD patients and healthy controls (Fig. 1). An additional muscle biopsy sample was obtained from HD patients 26 weeks before beginning of the training intervention to assess alterations due to the natural disease progress.

At the beginning of the study, there were no differences in myocellular characteristics between HD patients and healthy controls (Fig. 2). Satellite cell content per MyHC-1 fiber $(P=0.014)$ and per MyHC-1 myonucleus $(P=0.006)$ increased significantly in healthy controls during the endurance training intervention, whereas it remained constant in HD patients $(P=0.804$ and $P=$ 0.975 for satellite cell content per MyHC-1 fiber and myonucleus, respectively). There was a significant group $\mathrm{x}$ time interaction for satellite cells per $\mathrm{MyHC}-1$ myonucleus $(P=0.045)$. All further variables were not altered during the training intervention in HD patients and healthy controls. During the natural course observation period in HD patients, there were no fiber type-specific alterations in any variable.

Similar skeletal muscle characteristics between HD patients and healthy controls at baseline suggested similar potential for myofiber remodeling in response to exercise and indicated that these characteristics are not affected by pathological processes in the early- and midstage of the disease. This observation was further supported by the constant myocellular characteristics during the half-year natural course observation period. However, the missing satellite cell response in MyHC-1 myofibers following a half-year endurance training intervention in $\mathrm{HD}$ patients pointed to a potential dysregulation in the exercise-induced activation and/or proliferation of satellite cells. Due to the absence of new genetic material to replace damaged DNA, tissue remodeling might be impaired in subsequent years, resulting in an attenuation of myofiber regeneration. In conclusion, our result points to impaired myonuclear turnover in HD patients that might be associated with the clinical observation of skeletal muscle wasting in the longer-term.

\section{Acknowledgements}

We are grateful to all patients and participants for their contribution to this study. The authors kindly thank H. Fischer and E. Osuna for their support during data analysis. Imaging was performed with equipment maintained by the Centre for Microscopy and Image Analysis, University of Zurich.

\section{Authors' contributions}

SMM, SF, HHJ, MT were involved in the design of the study. SMM, VM, SF, JP, MLA, DA, HHJ contributed to data acquisition and analysis. SMM, DA, MF, HHJ, MT interpreted the data. SMM and MT drafted the work. VM, SF, JP, MLA, DA, MF, HHJ critically revised the manuscript. All authors approved the final version of the manuscript.

\section{Funding}

This study was supported by grants from the Swiss National Science Foundation (3200300_135539) and the Jacques and Gloria Gossweiler Foundation.

\section{Availability of data and materials}

The datasets used and/or analyzed during the current study are available from the corresponding author on reasonable request.

\section{Ethics approval and consent to participate}

All patients and participants had completed a routine health questionnaire and were informed about the applied procedures and the associated risks. Patients and participants provided written informed consent for participation in the study. All experiments were approved by the local ethics committee and the study was performed in accordance with the ethical standards laid down in the Declarations of Helsinki for human experimentation. This trial was registered on ClinicalTrials.gov (NCT01879267).

\section{Consent for publication}

Not applicable.

\section{Competing interests}

The authors declare that they have no competing interests.

\section{Author details}

${ }^{1}$ Department of Neurology, University Hospital Zurich, Zurich, Switzerland. ${ }^{2}$ Research and Performance Center for Elite Athleticism, OYM, Lorzenparkstrasse 12, 6330 Cham, Switzerland. Institute of Human Movement Sciences, ETH Zurich, Zurich, Switzerland. ${ }^{4}$ Department of Orthopaedics, Laboratory for Muscle Plasticity, Balgrist University Hospital, University of Zurich, Zurich, Switzerland.

Received: 11 April 2019 Accepted: 4 June 2019

Published online: 11 June 2019

\section{References}

1. Arenas J, Campos Y, Ribacoba R, et al. Complex I defect in muscle from patients with Huntington's disease. Ann Neurol. 1998;43:397-400.

2. Gehrig SM, Petersen JA, Frese S, et al. Skeletal muscle characteristics and mitochondrial function in Huntington's disease patients. Mov Disord. 2017; 32:1258-9.

3. Lodi R, Schapira AH, Manners D, et al. Abnormal in vivo skeletal muscle energy metabolism in Huntington's disease and dentatorubropallidoluysian atrophy. Ann Neurol. 2000;48:72-6.

4. Saft C, Zange J, Andrich J, et al. Mitochondrial impairment in patients and asymptomatic mutation carriers of Huntington's disease. Mov Disord. 2005; 20:674-9.

5. Zielonka D, Piotrowska I, Marcinkowski JT, Mielcarek M. Skeletal muscle pathology in Huntington's disease. Front Physiol. 2014;5:380. 
6. Mielcarek M, Smolenski RT, Isalan M. Transcriptional signature of an altered purine metabolism in the skeletal muscle of a Huntington's disease mouse model. Front Physiol. 2017;8:127.

7. Mielcarek M, Isalan M. A shared mechanism of muscle wasting in cancer and Huntington's disease. Clin Transl Med. 2015;4:34.

8. Cubo E, Rivadeneyra J, Gil-Polo C, Armesto D, Mateos A, Mariscal-Pérez N. Body composition analysis as an indirect marker of skeletal muscle mass in Huntington's disease. J Neurol Sci. 2015;358:335-8.

9. Frese $\mathrm{S}$, Petersen JA, Ligon-Auer $\mathrm{M}$, et al. Exercise effects in Huntington disease. J Neurol. 2017;264:32-9.

10. Pratley RE, Salbe AD, Ravussin E, Caviness JN. Higher sedentary energy expenditure in patients with Huntington's disease. Ann Neurol. 2000;47:64-70.

11. Süssmuth SD, Müller VM, Geitner $C$, et al. Fat-free mass and its predictors in Huntington's disease. J Neurol. 2015;262:1533-40.

12. Mueller SM, Gehrig SM, Petersen JA, et al. Effects of endurance training on skeletal muscle mitochondrial function in Huntington disease patients. Orph J Rare Dis. 2017:12:184.

\section{Publisher's Note}

Springer Nature remains neutral with regard to jurisdictional claims in published maps and institutional affiliations.

Ready to submit your research? Choose BMC and benefit from:

- fast, convenient online submission

- thorough peer review by experienced researchers in your field

- rapid publication on acceptance

- support for research data, including large and complex data types

- gold Open Access which fosters wider collaboration and increased citations

- maximum visibility for your research: over $100 \mathrm{M}$ website views per year

At BMC, research is always in progress.

Learn more biomedcentral.com/submissions 